\title{
Test yourself question: routine follow up after revision right total hip arthroplasty
}

\section{Molly B. Carnahan ${ }^{1}$. Jeremiah R. Long ${ }^{1}$}

Published online: 13 April 2020

(C) ISS 2020

Question: Routine follow up after revision right total hip arthroplasty.

68-year-old female seen in the orthopedic clinic for routine follow up 6 weeks following a revision right total hip arthroplasty for polyethylene liner wear induced osteolysis. The patient was asymptomatic at time of her 6 week postoperative follow-up (Figs. 1, 2 and 3).

The diagnosis can be found at https://doi.org/10.1007/s00256-020-03431-x

Molly B. Carnahan

carnahan.molly@mayo.edu

1 Department of Radiology, Mayo Clinic Arizona, 5777 E. Mayo Clinic Boulevard, Phoenix, AZ 85054, USA

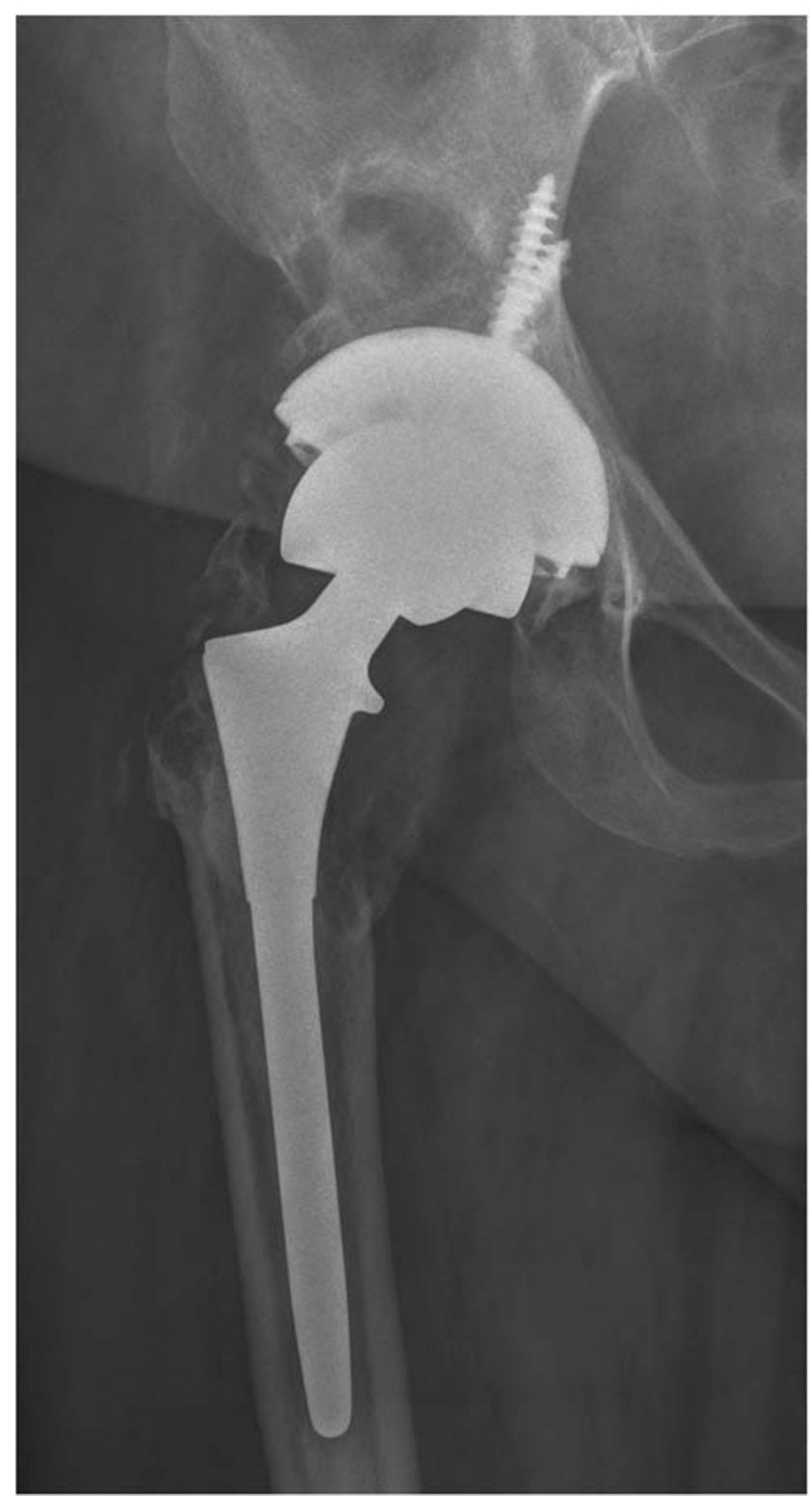

Fig. 1 AP radiograph of the right hip 6 weeks following revision total hip arthroplasty 


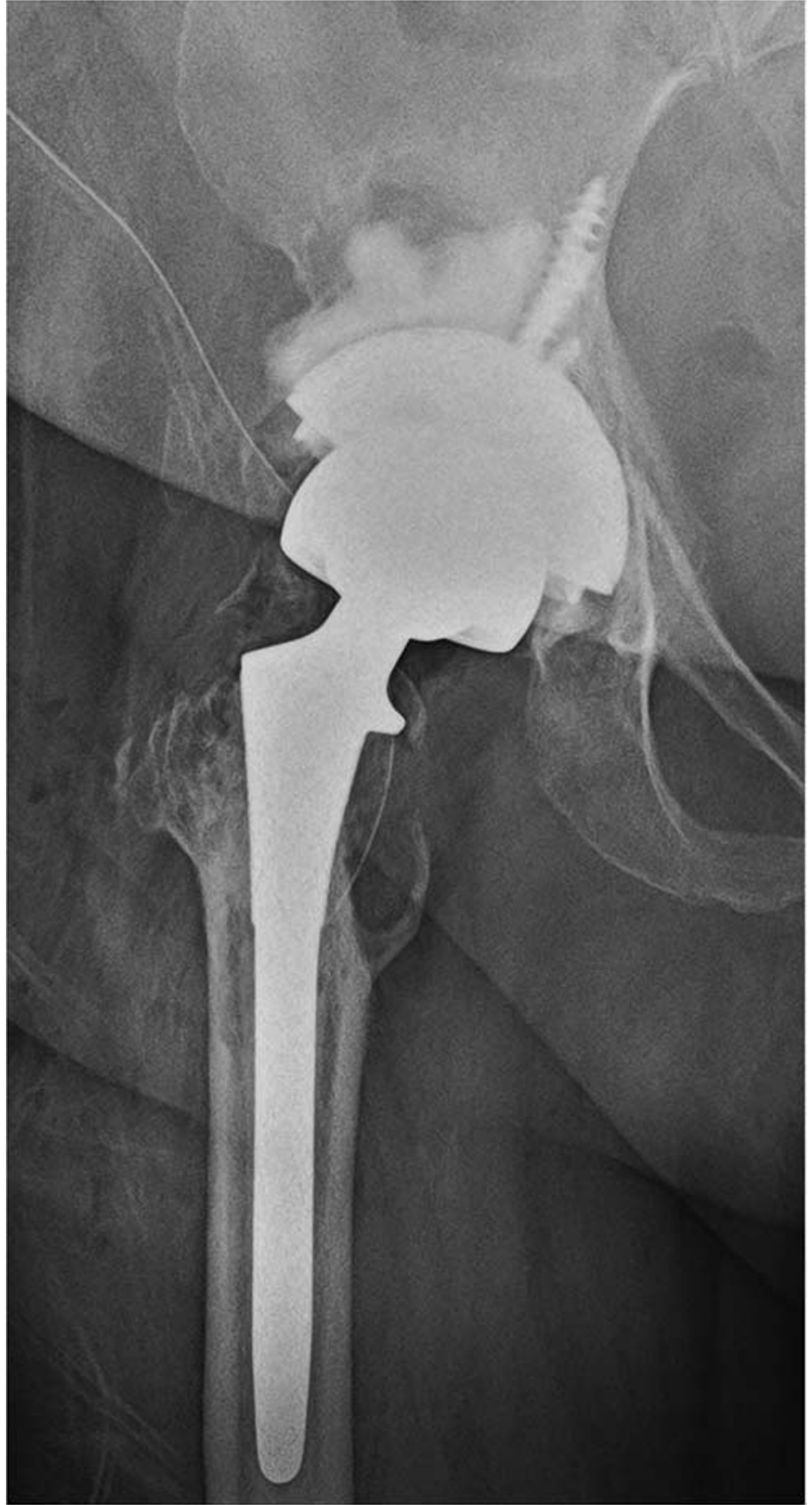

Fig. 2 AP radiograph of the right hip from 6 weeks earlier, immediately following revision total hip arthroplasty

Publisher's note Springer Nature remains neutral with regard to jurisdictional claims in published maps and institutional affiliations.

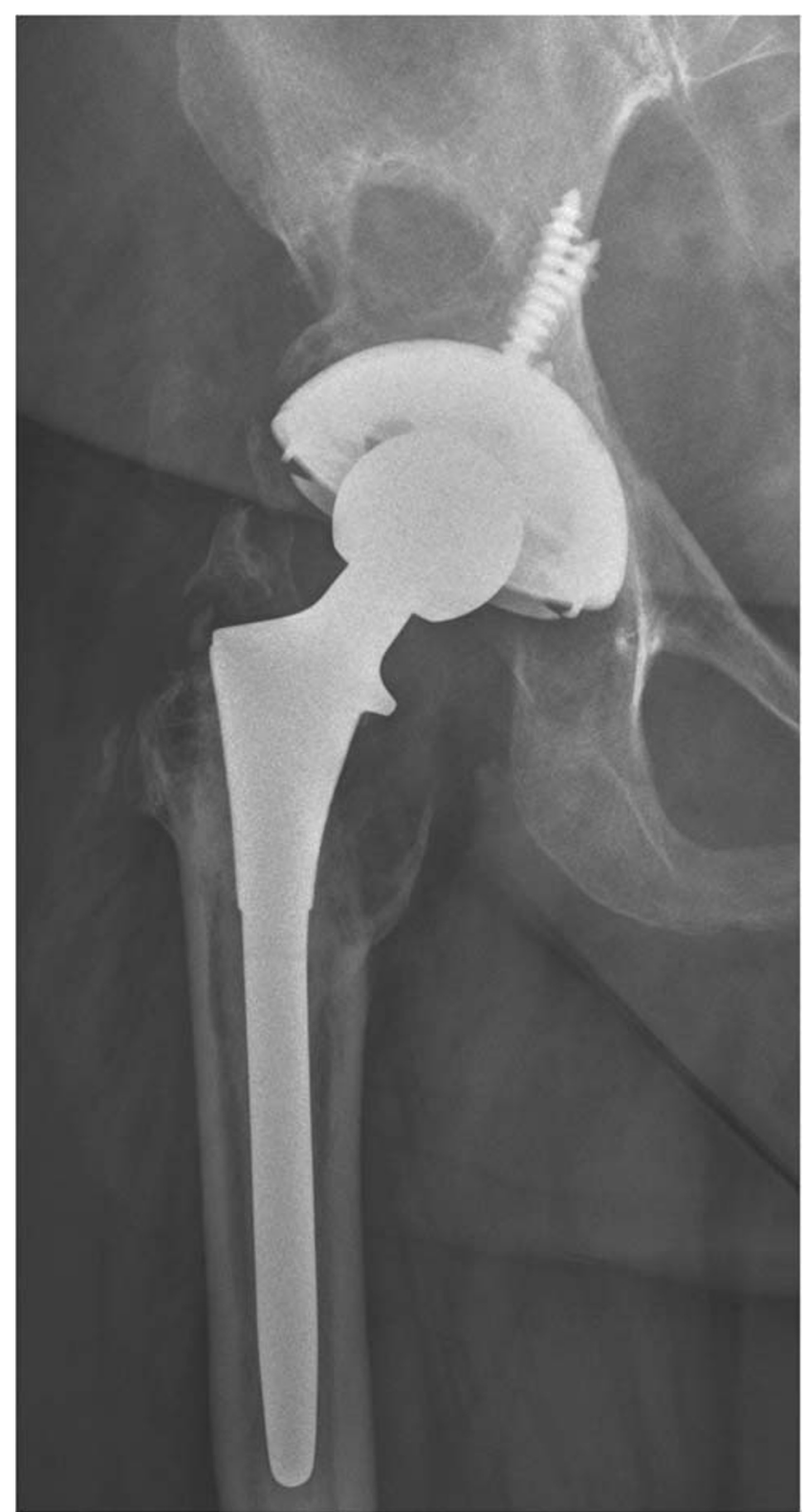

Fig. 3 AP radiograph of the right hip, pre-operatively 